Peer-Reviewed Article

ISSN: 2162-3104 Print/ ISSN: 2166-3750 Online

Volume 5, Issue 2 (2015), pp. 121-131

(C) Journal of International Students

http://jistudents.org

\title{
Evaluating the Struggles with International Students and Local Community Participation
}

\author{
Weronika A. Kusek, PhD \\ Department of Earth, Environmental, and Geographical Sciences \\ Northern Michigan University (USA)
}

\begin{abstract}
International students are not only important for universities, but even more so to the host communities, towns and regions where higher education institutions are located. This pilot study looked at a public university located in a small college town in Ohio. The study explored the relationship between international students and the local community. Data for this study was collected through questionnaires and conversations with international students from seven different countries, and complemented by participant observations. The outcomes of this study suggest that international students at the subject university feel a low level of engagement with the local community. Student questionnaires and conversations indicated that their daily schedules in the United States contained fewer activities and social interactions than in their home towns. The study explored potential reasons for this difference in daily routines and community engagement, as expressed by interviewed students.
\end{abstract}

Keywords: International Students, Higher Education, Local Communities, Student Engagement

The United States (U.S.) issued almost a half million student visas in 2011 and 400,000 the year before (United States Department of State, 2012). According to the U.S. Department of State (2012), the number of international student visas sought and issued is expected to steadily increase in the upcoming years. Based on observed trends over the last several decades, along with projected increases in students seeking educational opportunities abroad, academics have been analyzing international students' experiences in host countries (Bystydzienski \& Resnik, 1994; Gebhard, 2012; Ghosh \& Wang, 2003) and acknowledging specific issues such as perceived discrimination, loss of social status, loneliness and academic performance (McNamara \& Harris 1997; Rawlings \& Sue, 2013; Sarkodie-Mensah, 1998). According to McFadden, Maash-Fladung, \& Mallett (2012), universities in the United States are strategically recruiting students to their campuses for further income generation and to raise their institutions' international profile. McFadden et al. (2012,) noted, "Universities and colleges strive to create an 
environment on their campuses that is reflective of today's society and the world. [...] Populating our campuses with international students will encourage both international and domestic students to develop intercultural proficiency" (p. 158).

What is missing from the existing studies is a discussion concerning the relationship between international students and the local communities in which they reside while attending American institutions. International students are often limited by their own cultures and are sometimes confused with the American culture presented to them upon arrival (Ee, 2013). According to Ee (2013), the cultural shock experienced by international students in the USA has resulted in a noticeable separation and distancing from the main campus and community populations - sometimes further fueled by micro aggressions by the host population against the language and race of international students. A separation from the local community leads to international students generally gathering with students from similar cultural backgrounds and treating the outside world as unsupportive or even dangerous to their cultural values and lifestyles. International students tend to create temporary, small relational communities to survive their tenure at an American university, and they do not always participate in community activities outside of the campus because they find comfort through familiarity with people from their culture and background. The isolation of international students should be concerning because one of the motivating factors to study abroad is to immerse oneself in the culture of the host country. Conversely, their lack of wider community involvement makes them absent from the cumulative definition of the community outside the campus. What results, is not only a separation among the 'locals' and the 'internationals,' but also a lack of cultural exchange, which would be beneficial for both international students and the host community (Ahamad \& Szpara, 2003; Callaway, 2010; Ee, 2013; Hodge, 2002; Sabry \& Bruna, 2007).

This pilot study looked at a public university located in a small college town in Ohio as a case-study to explore the relationships international students have with the local community that hosts the university.

\section{International Student Mobility and Community}

Among host countries around the world, the United States is the number one destination for international students (Kretovics, 2011). Hazen and Alberts (2006) suggest that foreign students are attracted to the United States because of the quality of education, opportunities to study/conduct research in their fields of particular interest, employability, and the funding opportunities available to them (especially at the graduate level). The Association of International Educators estimates that foreign students and their dependents contributed approximately $\$ 20.23$ billion to the U.S. economy during the 2010-2011 academic year (NAFSA, 2012), which according to McFadden et al. (2012) makes international students "a key factor in promoting economic development" (p. 158). International students are not only important for universities, but even more so to the host communities, towns and regions where these higher education institutions are located.

American universities emphasize increasing their international student population each year - recognizing the value in increased diversity, but also towards generating revenue (Adnett, 2010; Altback, 2004; Haigh, 2002; McFadden et al., 2012). In realizing the importance of attracting international students to their campuses, administrators have not only created special offices and departments to serve international student populations on campuses, but institutions are also adopting sophisticated strategies and marketing techniques to recruit students in their

Summer 2015

http://jistudents.org

Volume $5 \bullet$ Issue 2 
home countries (Fischer, 2011; Haigh, 2010; Mallett \& McFadden, 2009; McBurne, 2000; Warwick, 1999). The competitive nature among institutions to attract international students is fueled by many challenges faced by universities in the United States; including demographic shifts among the student body - or what some scholars refer to as the privatization of universities (Kretovics, 2011). Administrators seek new students who are able to not only cover their tuition without the support of lenders, but who can also successfully complete their degrees within a short period of time to improve the rank of a university - thus "feeding this country's obsession with winning" (Kretovics, 2011, p. 11).

The attractiveness of international students has resulted in the fact that American universities are now competing with one another in this global market (Kretovics, 2011). In order to prevail, universities in the U.S. have started to look into issues that international students face while on campus, such as culture shock (Adler, 1975; Oberg, 1960; Rawlings \& Sue, 2013), adjustment problems (Gebhard, 2012), linguistic barriers (Kuo, 2011), immigration restrictions (Sarkodie-Mensah, 1998; Starobin, 2006) and psychological distress associated with moving to a foreign country (Bennett, 1986). These issues have been studied and assistance programs targeting these problems have been implemented on many American campuses. There are dedicated offices that offer advice and support needed to ease the transition to an American institution (Sarkodie-Mensah, 1998). Global education offices organize academic support programs that include: writing institutes/workshops, library resources, orientation sessions and regular meetings to offer support for students who arrive from all over the globe. Despite much emphasis on providing and offering a supportive/welcoming environment, it seems many universities have not yet taken advantage of leveraging their local communities to achieve the same competitive advantage.

In relating community to this discussion, the independent movement of people is argued to be fueled by globalization, which continues to have an impact on spatial contestations and local interactions (Castree, 2003; Oxfeld, 1998; Wall, 2000). Researchers across disciplines came to the consensus that community interactions are essential for cultural adaptation (Ruben \& Kealey, 1979). Central to this argument is how people strive to achieve a sense of community (Castellini, Colombo, Maffeis, and Montali, 2011; Keller, 2003; Tinder 1980; Trager, 2001). Geographically, communities are defined by boundaries (Agnew, 1987); however, Massey and Jess (1995) further argued that people construct personal and communal identities to purposely separate themselves from the rest of the society. It is the very spaces people reside in that allows individuals to define the physical boundaries and create specific identities (Suttles, 1972) and a sense of belonging (Block, 2009). Poplin (1979) notes, communities "involve homes, shops, and cultural venues that define the local setting. People residing in a location interact among each other in place based locations to structure a "sense of belonging" (p. 23). Moreover, Suttles (1972) pointed out that "people use territory, space, and movement to build collective representations that have communicative value" (p. 7). The potential absence of international students in the "homes, shops, and cultural venues that define the local setting", can therefore be perceived to mean that, quite literally, international students are thus absent from the larger local community that defines its boundaries via these venues. As Suttles (1972) indicated, that absence translates into the way the community as a whole perceives itself, and how it is perceived from the outside -university towns fail to communicate the international, multicultural wealth that they are concealing within university walls. 


\section{Case-Study: Ohio Public University and the Host Town}

The study subjects were a public university in Ohio and the town in which the university is located. The town has a local population of 29,000 residents, which constitutes just over a half of population in this area. The other half of the population comes from Ohio Public University (fictional name for this study) which hosts 27,000 undergraduate and graduate students on the main campus. Of the student population, two thousand are international students from approximately 99 different countries. The number of international admissions at the university has been growing every year, and there was an increase of $35 \%$ in international enrollment between the 2010 and 2011 academic years (Kent State University, 2011). Most international students come from China (772 students), Saudi Arabia (309 students), and India (142 students) (Kent State University, 2011). Among these international students at Ohio Public University, $20 \%$ reside in dormitories, $15 \%$ in apartments and private homes, directly contributing to the town's economy, and 5\% with their immediate or extended families. Contributions to the local economy extend beyond funds spent on accommodations. While specific data for the student population at Ohio Public University is not available, in general over $8.5 \%$ of international students in Ohio are married and $85 \%$ of them bring their families to reside with them in Ohio (NAFSA, 2012). Thus, the town hosting Ohio Public University was able to benefit from a portion of the net foreign student contribution to Ohio's economy estimated at over \$662 million for the 2010-2011 academic year (NAFSA, 2012). Ohio Public University and the host town also benefit from less tangible products of hosting a large population of international students. International students provide diverse perspectives in their academic work, and improve the overall educational experience for all students enrolled at the university. Finally, despite the fact that they remain unexplored, international students also bring a wide variety of consumer behaviors and lifestyle preferences that could fuel the existing businesses in this college town, but also inspire the creation of a diversity of cultural, culinary, and entertainment options. It is therefore crucial for the University and the town to continue to attract a broad and diverse population from around the world.

\section{Research Method}

This research was designed as a qualitative pilot study. Cultural geographers, among other researchers with social science background, are interested in the spatiality of everyday life at multiple and fluid scales (Holloway \& Hubbard 2000) and often find qualitative methodologies central to conducting successful and thorough research projects (Kusek \& Smiley, 2014). Qualitative methodologies, such as interviews or descriptive questionnaires, are well-suited to provide an insight into personal and lived experiences of research subjects (Jackson 1983). In order to assess international students' perceptions of their host community at Ohio Public University, the researcher applied a descriptive questionnaire (see Appendix 1) supplemented by unstructured post-survey conversations with participants and participant observation. For this pilot study, 26 students completed the questionnaires and participated in subsequent conversations (see Appendix 1). The group of participants was diverse in terms of nationality, representing China (7 students), India (7 students), Saudi Arabia (6 students), Bangladesh (2), Poland (2), Tanzania (1), and the Philippines (1). Twenty participants were undergraduate students and six were graduate students. At the time of this study, 11 participants lived in Ohio with their families, and eight of these families had children. 
The research was conducted within the town hosting the Ohio Public University, at both on-campus locations and off-campus student homes. On-campus locations included the university library, dining halls, and student center. The principal investigator attended a variety of social events on campus organized by the office of Global Education such as the International Cook-Off, and the Saudi Day on campus. The principal investigator also dined with participants in off-campus ethnic restaurants, and visited students at their homes to observe their daily activities.

To recruit students to participate in this pilot study the researcher required support from the University's Global Education Office. The director sent out an invitation to students explaining the purpose of the study. The participants of this study volunteered to participate in the research, and were contacted by the researcher to set up interview and questionnaire meetings. The study began by asking participants to complete two questionnaires. One questionnaire pertained to how students spend time during an average day in their home towns in their country of origin, and the other questionnaire was focused on the students' lifestyle in their current town in Ohio. Both questionnaires were designed around blank time blocks for each halfhour and participants were asked to fill-in appropriate time-blocks with descriptions of activities they perform in the college town as well as their home towns during designated hours of the day. By assessing both activities, those at home and in the United States, the questionnaire offered the researcher insight into differences in the students' lifestyle in the American-based college town compared to the participants' home. After the questionnaires were completed, the researcher engaged in conversations with all study participants, and employed participant observation to gain further insight into the participants' lifestyles.

Post-interview conversations allowed the researcher to further discuss matters and experiences pertinent to critically understanding the differences between the daily routines of the participants in their home countries and how their daily routines in the United States differ or have been altered to adjust to a changing lifestyle. Participant observations further supplemented and supported the knowledge acquired from the questionnaire and conversations. In this regard, the data gathered for this study guided the interpretation and the direction of the analysis. Incorporating multiple methods reinforces and strengthens meanings that emerge (Elwood, 2010). Participant observation complemented other research methods by challenging existing perspectives and allowed the researcher to gain a subsequent detail and understanding into the lives of the research participants in their collective gatherings and evaluate their activities. For example, attending invitations to Saudi Day on campus allowed the researcher to experience Saudi Arabian culture, and this allowed for additional conversations with students, thus offering further insight into the life of this particular student population in their Ohio residence and how they interact while abroad. Additionally, the students from India also invited the researcher to their cultural functions, meals, and gatherings offering further insight into the students' lifestyles in the college town. During participant observations, numerous topics were discussed such as struggles adjusting to the American reality, frustrations associated with being away from home and common familiarities and general difficulties residing in a foreign country. To touch on these topics and to further develop an understanding based on the objectives of this study, during participant observations conversations were directed at soliciting information regarding the students' perceptions of the college town and the community.

It is important to highlight that this study was not explicitly designed to account for cultural differences between the local town and specific ethnic groups of international students, but rather at identifying broad patterns in behaviors, perceptions, and preferences which may 
inhibit community engagement. Nevertheless, during the data collection process, it became evident that in addition to general themes, individual ethnic groups have varying cultural reasons for their perceptions, preferences, and lifestyle choices. I felt that highlighting these cultural peculiarities would emphasize the diversity of needs that local communities may account in developing a strategy for the engagement of international students.

Answers to questionnaires were reviewed by the researcher with consideration for the information gathered via follow-up conversations and participant observation. In interpreting the data gathered, the researched focused on identifying common themes but also highlighting interesting comments or opinions which could serve as a foundation for further research.

\section{Findings}

It is important to first recognize and acknowledge the engagement and participation of international students in this research aimed at understanding the presence of international students in host university communities. Based on the results and discussion below, this study of international students at a major university in Ohio indicates that the international students do not necessarily feel engaged in their local city community.

This observation first derives from comparing international students' lives in their home countries and their lives in Ohio. The researcher found that students are satisfied with the university and the quality of education they are receiving, but they suffer from the lack of involvement in the local community. Several students have indicated that the college town is too small, too isolated and is insufficiently exciting. Three students mentioned that after completing thirty credit hours they are planning to transfer to a different school, and this decision is based on the physical environment, not the quality of education. All participants agreed that they are satisfied with the quality of education that the university provides, and they appreciate the campus facilities that the institution offers. At the same time, one student claimed that this smaller college town, although quite boring, is a good place when you arrive to the U.S. with family. He said: "it is safe here, and I don't have to worry about my wife".

Based on the students participating in this study, international students in this college town in Ohio have a strong connection to campus but not to the greater town community. The majority of these students' lives do not exceed beyond the university campus. The questionnaires indicate that students who participated in this pilot project rarely visit shops in the downtown area and only occasionally visit restaurants. When comparing the activities students would partake in at home to the college town in Ohio, big differences in general everyday lifestyles were observed. There were several examples of students who led much more socially active lives when at home: in particular Chinese students indicated that in China they spent a lot of their spare time in malls and meeting friends for coffee or ice-cream, and such activities were mostly absent from their experiences in Ohio. The students from Saudi Arabia indicated that in their country of origin they interact more often with other males by playing soccer, spending their spare time in male-only locales, going to smoke Hookahs, visiting mosques or racing cars in the desert.

When students were asked to include the places where they spend their spare time in the American college town, the majority of the students included university buildings such as the student center, university library, computer labs or the recreational center. The library and recreational center were the most commonly listed places in the questionnaire. The only place outside of campus acknowledged by all students participating in this survey was the local 
Walmart because most of them later mentioned this is where they shop for groceries. In fact, one student from Saudi Arabia told me that "all the employees in Walmart know me by now, because this is the only place I go to." The only other store several students included in the questionnaire was the International Home Market, which is an international food store located in downtown, and Target which is several miles away in a neighboring town.

Several students from Saudi Arabia, China and India indicated that they do not feel comfortable going into downtown. For example, one Chinese student specified that they do not go to bars because, as the student noted: "my parents told me not to go to bars as nothing good happens there. I would go but only with an American friend." This comment was interesting in the sense that it relates back to the theoretical framework introduced earlier - a sense of belonging is established when people residing in a location interact with each other in place based locations. Thus, a key to community engagement of international students may lie in providing opportunities for international students to interact personally with domestic students in local community locations. Unfortunately, as Gebhard (2012, p. 187) points out, creating these place based locations for domestic and international students may be difficult due to initial barriers to communication. Gebhard (2012) provides an example of a female Thai student who feels uncomfortable with her American roommate "sitting on her bed with shoes on or by changing her clothes in front of her." Such cultural differences often make it uncomfortable for both the international student and the domestic student to personally interact. Consequently, international/domestic students fail to create the opportunity to share experiences in local community locations. As discussed by students in conversations, several students noted the fact that people from different cultures do not always feel comfortable reviewing lifestyle related questions with domestic students; rather hoping to establish relationships organically - which can take months, if not years, to develop.

Fifteen of the student participants indicated they typically meet with other people from their own ethnic communities regularly—such as private spaces (i.e. someone's home). Although it is determined in this study that students tend to gather with other students from similar ethnic and cultural backgrounds, it has also been discussed that international students often meet with other international students from different countries to share unique aspects/elements of their culture. This was made evident by several students who mentioned in conversations that on weekends and evenings it is common practice to visit friends and share meals with other fellow international students. It was also common for students to attend on-campus activities organized by campus organizations or the Global Education Office. A student from Tanzania said:

I love gathering with my international friends on weekends. Although, we come from different corners of the world we can relate to each other. We have the same problems, we face cultural and financial obstacles, and we all miss home. We cook together, talk, watch pictures from our countries, and pray together.

When students described their eating habits many differences could be observed, some of which should be considered by local businesses in this college town. During conversations with several Saudi students, believe that the college town should have more diverse restaurants that would cater to their tastes, and more importantly restaurants should be open at later hours that suit their living style. One student said: "the only place you can eat dinner at $11 \mathrm{pm}$ is Sheetz [gas station with ready-food section]." This is a major cultural difference that has been observed 
where it is more common for restaurants to remain open later in Middle Eastern countries because of the local climate-because it is cooler in the late-evening and early-morning hours.

In addition to eating patterns as an obstacle to community engagement, students from India and Poland identified pricing as an impediment to more frequently visiting community food venues. Students from India and Poland expressed the belief that food is overpriced and is not diverse enough. Indian students mentioned, for instance, the Student Center which serves Indian food but noted that the selection is very limited and pricy. Four Indian students wrote on the questionnaire that on Saturdays they have lunch at an Indian restaurant located in a nearby small town. The Polish doctoral students said that due to the relatively high prices in restaurants they only go to restaurants on special occasions such as anniversaries or birthdays and "namedays' that they celebrate.

The questionnaires also indicated that the Saudi Arabian, Indian and Chinese students do not feel comfortable with going to places that serve alcohol or where alcohol is being consumed. Therefore, if there are bars that serve food at night, international students tend to avoid these establishments because many of these students do not perceive them as safe or welcoming spaces. There are a host of investment opportunities that could aim to create spaces which international students (especially those arriving from non-Western cultures) would consider safe alternatives, and such establishments which may also attract a local crowd because of the opportunity to experience another cultural setting. For example, there is one Hookah bar, however Saudi students who were interviewed did not find it a desirable or safe place to visit. Saudi students noted that in their home country they regularly attended Hookah bars, but in Ohio they were instead gathering together at their apartments to engage in Hookah smoking. When the Saudi students were asked to provide a reason for this difference, their response was they perceive the downtown area in the evening as iniquitous. Perceptions of places may create barriers, and sometimes misunderstanding places can make community interactions difficult for international students. As Ruben and Kealey (1979) note, community interactions are essential for cultural adaptation, and any isolation creates an environment of separation and exclusion. This has been observed in this study.

Several students from different background commented on religion. Chinese students noted the importance of local worship places towards accommodating the international population. One student from China for instance found the local church very welcoming, and said that he visits a local church each week. When asked about his experience with the church, he mentioned "the church staff is very nice, welcoming and provides free dinner once a week." Saudi students indicated that when they are in Saudi Arabia they frequently visit Mosques, but in the college town such opportunities are very limited. Other responses indicated curiosity about religious life which was absent at home. One student noted: "I do not know what religion is all about, you know in China I never went to church. I would like to go to church here in the United States to see what it is." This shows that international students are interested in experiencing the local culture, but as acknowledged above, many find it difficult to establish relationships which, in the end, is necessary to enable international students to pursue their curiosity.

One final point to consider, migrants maintain transnational networks with their families and friends and never fully feel like they have moved to another country (Ryan, Sales, Tilki, \& Siara, 2008). Students who participated in this project stay in touch often with their family back home. All students marked Skype - the internet-based voice and video application - as a means of communicating with family back home as either their daily or weekly activity. Skype videoconferencing enables students to maintain their personal networks at home on a regular basis but 
at the same time it limits their interaction with the local community in the United States. Capitalizing on such lifestyle changes may be another opportunity to involve international students in the entertainment activities in Ohio - maybe pioneering Skype-enabled restaurants is one revolutionary idea which may just work.

\section{Conclusion}

Although the number of students who participated in this study was small, the objectives of this pilot study were to identify future areas for research to evaluate in more depth the struggles that international students have with immersing themselves in the local community. While inconclusive and requiring further analysis, this study pointed to a large gap between the diversity of locations and activities pursued by international students in their home towns and the American host university town. For the author, the areas of particular interest can be identified around three themes. First, international students are either most comfortable among others students from their cultural/regional background, or among other international students. What is interesting is that in addition to limiting their personal network, groups of international students also limit their use of locations to private residences and university property. Exploring the decisions behind selecting their personal network of friends, and selecting the location for cultivating that network could be one area of further study. One reason that may be influencing the selection of location is fear and misperception. Many students featured in this study identified the downtown location as unsafe, or iniquitous. At the same time, they indicated that they use those establishments which are essential to maintaining their daily functions - shopping for groceries, reading, studying, communicating with family. Thus, a second area of study could focus on how centralizing essential services and retail offerings in close proximity to nightlife offerings of university towns could influence their general appeal to international students. Finally, while not unanimously quoted by all students, some students mentioned the cost of engaging in activities outside of the university as discouraging. International students come from diverse backgrounds and represent varying levels of affluence. Nevertheless, the principal investigator would like to understand what types of free or university sponsored activities could be organized by university towns to remove pricing from the list of obstacles to community engagement. These topics of inquiry generally and individually represent an underexplored area and more research is needed to assess such perspectives and perceptions of the international student experiences. While this study has indicated certain patterns, behaviors and perceptions that international students at this major university in Ohio exhibit, the nature of such research can be replicated by university towns across the U.S. to further identify similarities, or to determine if other case-specific trends emerge. Based on the findings of this pilot study, the impact from subsequent work will result in attempts to establish programs aimed at making international students feel more involved/engaged in the lifestyles and the physical environment of the local community.

\section{ACKNOWLEDGMENTS:}

I have collected data for this article while I was working on my doctoral degree at Kent State University. I would like to thank the Department of Geography at Kent State University for facilitating an academic environment where students felt encouraged to work on projects that 
were independent of their doctoral dissertation. I would also like to thank Dr. Nick Wise for his support and mentorship during the writing process.

\section{REFERENCES}

Adler, P. (1975). The transitional experience: An alternative view of culture shock. Journal of Humanistic Psychology, 15(4),13-23.

Adnett, N. (2010). The Growth of International Students and Economic Development: Friends or Foes? Journal of Education Policy, 25(5), 625-637.

Agnew, J. A. (1987). Place and politics. Boston, MA: Allen and Unwin.

Ahamad, I., \& Szpara, M.Y. (2003). Muslim children in urban America: The New York City Schools experience. Journal of Muslim Minority Affairs, 23, 295-301.

Altbach, P. (2004). Higher Education Crosses Borders:.Change: The Magazine of Higher Learning, 18-25.

Block, P. (2009). Community: The structure of belonging. San Francisco: Berrett-Koehler. Bystydzienski, J. (1994). Women in cross-cultural transitions. Bloomington, IN: Phi Delta Kappa Educational Foundation.

Callaway, A. (2010). Literature Review: The growing need to understand Muslim students. Multicultural Perspectives, 217-222.

Castellini, F., Colombo, M., Maffeis, D., \& Montali, L. (2011). Sense of community and interethnic relations: Comparing local communities varying in ethnic heterogeneity. Journal of Community Psychology, 663-677.

Dowler, L. (2001). The Four Square Laundry: Participant Observation in a War Zone. Geographical Review, 414-414.

Ee, J. (2013). "Is he an idiot!" Experiences of international students in the United States. Journal of International Students, 3(1), 72-75.

Elwood, S. (2010). Mixed methods: Thinking, doing, and asking in multiple ways. In The SAGE handbook of qualitative geography, eds. D. DeLyser, S. Herbert, S. Aitken, M. Crang, and L. McDowell, 94-113. London: SAGE.

Fischer, K. (2011). State by state, colleges team up to recruit students from abroad. Chronicle of Higher Education, p. 23.

Gebhard, J.G. (2012). International students' adjustment problems and behaviors. Journal of International Students, 2(2), 184-193.

Ghosh, S. \& L. Wang. (2003). Transnationalism and identity: a tale of two faces and multiple lives". The Canadian Geographer, 47(3), 269-282.

Haigh, M.J. (2002). Internationalization of the Curriculum: Designing inclusive education for a small world. Journal of Geography in Higher Education, 26(1), 49-66.

Hodge, D. R. (2002). Working with Muslim youths: Understanding the values and beliefs of Islamic discourse. Children \& Schools, 24, 6-20.

Holloway, L. \& Hubbard, P. (2000). People and place: the extraordinary geography of everyday life. New York, NY: Prentice Hall.

Jackson, P. (1983). Principles and problems of participant observation. Geografiska Annaler, Series B, Human Geography, 65 (1), 39-46. 10.

Keller, S. (2003). Community: Pursuing the dream, living the reality. Princeton, NJ: Princeton University Press.

Kent State University. (2011). International Students Enrolled at Kent State University Fall

Summer 2015

http://jistudents.org

Volume $5 \cdot$ Issue 2 
2011- Represented Countries, Territories and Class Levels. University 15th Day Report, September 2011.

Kretovics, M. (2011). Business practices in higher education a guide for today's administrators. New York, NY: Routledge.

Kuo, Y-.H. (2011). Language challenges faced by international graduate students in the United States. Journal of International Students, 1(2), 38-42.

Kusek, W. \& Smiley, S. (2014). Navigating the city: gender and positionality in cultural geography research. Journal of Cultural Geography, 31(2), 152-165.

Mallett, W. \& McFadden C. (2009). Recruitment practices and college choice factors that influence international undergraduate enrollment. Global Education Journal, 2, 132-141.

McBurne, G. (2000). Pursuing internationalization as a means to advance the academic mission of the university. Higher Education in Europe, 25(1), 63-73.

McFadden, Ch., Maash-Fladung C, \& Mallett W. (2012). Recruiting International Students to Your Campus. Journal of International Students, 2(2), 157-167.

McNamara, D. \& R. Harris (1997). Overseas Students in Higher Education. Routledge: London.

National Association of Foreign Student Advisers - Association of International Educators. (2012). The Economic Benefits of International Education to the United States for the 2010-2011 Academic Year: A Statistical Analysis. Retrieved from http://www.nafsa.org/_file/_/eis2011/usa.pdf

Poplin, D. (1972). Communities: A survey of theories and methods of research. New York, NY: Macmillan.

Rawlings, M. \& Sue E. (2013). Preparedness of Chinese Students for American Culture and Communicating in English. Journal of International Students, 3(1), 29-39.

Ryan, L., Sales, R., Tilki, M., \& Siara, B. (2008). Social Networks, Social Support and Social Capital: The Experiences of Recent Polish Migrants in London. Sociology, 672-690.

Sabry, N., \& Bruna, K. (n.d.). Learning from the Experience of Muslim Students in American Schools: Towards a Proactive Model of School-Community Cooperation. Multicultural Perspectives, 44-50.

Suttles, G. (1972). The social construction of communities. Chicago, IL: U. of Chicago Press.

Tinder, G. (1980). Community: Reflections on a tragic ideal. Baton Rouge, LA: LSU Press.

Trager, L. (2001). Yorba hometowns: Community, identity, and development in Nigeria. Boulder, CO: Lynne Rienner Publishers.

United States Department of State (2012). Multi-Year Graphs. Retrieved from http://travel.state.gov/visa/statistics/graphs/graphs_4399.html

Warwick, D. (1999). Globalisation: challenges and opportunities for UK higher education. In Keynote at Association of University Administrators Conference.

\section{About the Author}

Weronika Kusek is an assistant professor in the Department of Earth, Environmental and Geographical Sciences at Northern Michigan University. Dr. Kusek is a human geographer interested in migration, globalization, urbanism, and qualitative methods used in cultural geography. She completed her PhD from Kent State University. E-mail: wkusek@nmu.edu 